\title{
Hypertonic saline increases tight junction permeability in airway epithelium
}

\author{
M. Högman*, A-C. Mörk", G.M. Roomans"
}

Hypertonic saline increases tight junction permeability in airway epithelium. M. Högman, A-C. Mörk, G.M. Roomans. C ERS Journals Ltd 2002.

ABSTRACT: Asthmatics are known to react to inhaled hyperosmolar solution. Therefore, the effect of hyperosmolar salt solutions on tight junctions of the airway epithelium was investigated by electron microscopy.

Rat trachea was perfused with different concentrations of sodium chloride $(\mathrm{NaCl})$ and then fixed from the luminal side with glutaraldehyde to which the electron dense tracer lanthanum chloride had been added.

Lanthanum penetrated $3 \pm 1 \%$ of the tight junctions in trachea perfused with 295 mOsm Krebs-Ringer's buffer (KRB). Adding NaCl to the KRB (KRB-NaCl) increased osmolarity of the solution. After perfusion with 589 or 876 mOsm KRB$\mathrm{NaCl}$, lanthanum was observed in the lateral intercellular spaces in $50 \pm 11$ and $57 \pm 6 \%$, respectively. The effect of hyperosmolarity was reversible and only $6 \pm 1 \%$ of the tight junctions were penetrated after perfusion with $295 \mathrm{mOsm}$ KRB solution following 589 mOsm KRB-NaCl perfusion. Adding mannitol to the KRB to an osmolarity of 589 mOsm only caused $5 \pm 1 \%$ of the tight junctions to open, even though osmotic effects were observed.

Opening the tight junctions with hyperosmolar salt solutions may play a role in exercise-induced asthma. It may also open the prospect for increased penetration of inhaled drugs into the interstitium and the circulation.

Eur Respir J 2002; 20: 1444-1448.

The function of tight junctions is to limit and control paracellular permeability in epithelia and to form a border separating the apical domain of the cell membrane from the basolateral domain. There is a substantial physiological variation in the "tightness" of the junctions, which appears to be based morphologically on the number of "strands" (as seen in freeze-fracture electron micrographs) joining the two neighbouring cells $[1,2]$. In addition, many substances are known to affect the permeability of the tight junction $[3,4]$.

Many factors regulating the permeability of tight junctions have been studied, mainly in connection with the blood-brain barrier [5], the mammary gland [6] and the intestinal epithelium, where it has been proposed that $\mathrm{Na}^{+}$-glucose cotransport would transiently increase the pore size of tight junctions, promoting passage of glucose by a paracellular rather than a transcellular route [7]. The respiratory epithelium has, however, received hardly any attention in this respect.

The airway epithelium (mainly its submucosal gland cells) actively secretes chloride ions both via a cyclic adenosine monophosphate (cAMP)-activated chloride channel in the apical membrane (the so-called cystic fibrosis transmembrane regulator) and via a calcium-activated chloride channel $[8,9]$. Water is transported with the chloride ions. The resulting fluid dilutes the airway mucus and contributes to the fluid bathing the cilia. The composition of the airway surface liquid has long been a matter of debate, but most data indicate that it is normally close to isosmotic [10-12]. It has been shown that inhalation of hypertonic solutions may elicit bronchoconstriction in asthmatics, and this phenomenon has been clinically used as a test for asthma $[13,14]$. The underlying mechanism is, however, unknown.

If hypertonic solutions could open tight junctions in the intestinal epithelium, it seemed possible that the effect of high concentrations of sodium chloride $(\mathrm{NaCl})$ in the airways could be mediated by a change in the permeability of the paracellular pathway. Adding lanthanum chloride to the luminal side of the epithelium tested this hypothesis. Normally, lanthanum ions would not penetrate the tight junctions, but if the permeability was increased by hypertonic solutions, the electron dense lanthanum could be visualised by electron microscopy in the lateral intercellular spaces.

\section{Materials and methods}

\section{Animals and preparation}

Sprague Dawley rats (body weight 250-410 g) were used in this study. The animals were deeply anaesthetised with sodium pentobarbital, the trachea was 
removed from the animal, cleaned of external muscle and connective tissue and rinsed in Krebs-Ringer's buffer (KRB). The KRB (containing $(\mathrm{mM}) 120 \mathrm{NaCl}$, $5.5 \mathrm{KCl}, 2.5 \mathrm{CaCl}_{2}, 1.2 \mathrm{MgCl}_{2}, 1.2 \mathrm{NaH}_{2} \mathrm{PO}_{4}, 20$ $\mathrm{NaHCO}_{3}$ and 11 glucose) was aerated with $95 \%$ oxygen $\left(\mathrm{O}_{2}\right)$ and $5 \%$ carbon dioxide $\left(\mathrm{CO}_{2}\right)$. A simplified perfusion system was used where the luminal and serosal fluids were separated. Glass pipettes were inserted in the open ends of the trachea and the trachea was sutured around the opening of the pipette. The inlet was a Pasteur pipette, of which the thin end was curved $\left(90^{\circ}\right)$ upwards. The trachea was then placed horizontally in a small Petri dish, which was filled with $\mathrm{KRB}$ at $37^{\circ} \mathrm{C}$. The test solutions were placed in the wide part of the Pasteur pipette and the inside of the trachea was perfused with the test solution at a hydrostatic pressure of $2 \mathrm{cmH}_{2} \mathrm{O}$. The Regional Committee on Animal Experiments, Uppsala, Sweden, approved the experimental protocol.

\section{Methods}

The KRB was made hyperosmotic by increasing the $\mathrm{NaCl}$ content. The following $\mathrm{KRB}$ solutions were used: isotonic $(295 \mathrm{mOsm}, 0.9 \% \mathrm{NaCl}), \mathrm{KRB}-\mathrm{NaCl}$ (589mOsm, $1.8 \% \mathrm{NaCl}$ and $876 \mathrm{mOsm}, 2.7 \% \mathrm{NaCl}$ ), and hypertonic mannitol (1.2 $\mathrm{M}$ in $\mathrm{KRB}$, corresponding to the osmolarity of $1.8 \% \mathrm{NaCl}$ ), all at $37^{\circ} \mathrm{C}$ and aerated with $95 \% \mathrm{O}_{2}$ and $5 \% \mathrm{CO}_{2}$. The tracheas were perfused for 4 min with the test solutions. In one experiment, tracheas were first perfused for $4 \mathrm{~min}$ with $1.8 \% \mathrm{KRB}-\mathrm{NaCl}$ and then for 2 min with $\mathrm{KRB}$.

At the end of the perfusion with test solution, the tracheas were perfused with the fixative, which was $2.5 \%$ glutaraldehyde in $0.1 \mathrm{M}$ sodium cacodylate buffer $\mathrm{pH}$ 7.2. To this fixative, $1 \%$ lanthanum chloride was added. The fixative was made isosmotic to the particular test solution used by addition of $\mathrm{NaCl}$. After the trachea was filled with the fixative, the ends were closed by suture and the trachea was kept overnight in $2.5 \%$ glutaraldehyde in cacodylate buffer. In addition, rat trachea was fixed in situ (i.e. without previous incubation).

The glutaraldehyde-fixed tissue was then postfixed with osmium tetroxide, dehydrated in a graded ethanol series and embedded in epoxy resin. Ultra-thin sections were cut and some of these were contrasted with uranyl acetate and lead citrate whereas others were left uncontrasted. The sections were viewed in a transmission electron microscope (Hitachi 7100; Hitachi, Tokyo, Japan) at $75 \mathrm{kV}$. The effect of the different test solutions was scored by determining the relative number of tight junctions that could be classified as "intact", "weakened" or "open". The data are based on double-blind analysis of two different sections from four animals in each group; in each section $73 \pm 8($ mean $\pm 95 \%$ confidence interval (CI)) tight junctions were scored.

\section{Analysis}

To compare data between groups, a one-way analysis of variance (ANOVA) was performed. For post-hoc comparisons the Tukey's honest significant difference test was applied and probability values were calculated. Results are presented as mean $\pm 95 \%$ CI. For correlation tests, the Spearman rank correlation (r) was used.

\section{Results}

With respect to penetration of luminally applied lanthanum into the paracellular space, three types of situations could be observed: 1) no penetration at all, "intact tight junctions" (fig. 1a); 2) penetration of lanthanum chloride for a short distance in the tight junction, "weakened tight junctions" (fig. 1b); and 3) penetration of lanthanum chloride through the entire junction into the lateral intercellular space, "open junctions" (fig. 1c). In nonperfused trachea, the fraction of the tight junctions of the "intact" type was $0.92 \pm 0.15$, and the remaining tight junctions were of the "weakened" type $0.08 \pm 0.14$. No "open junctions"
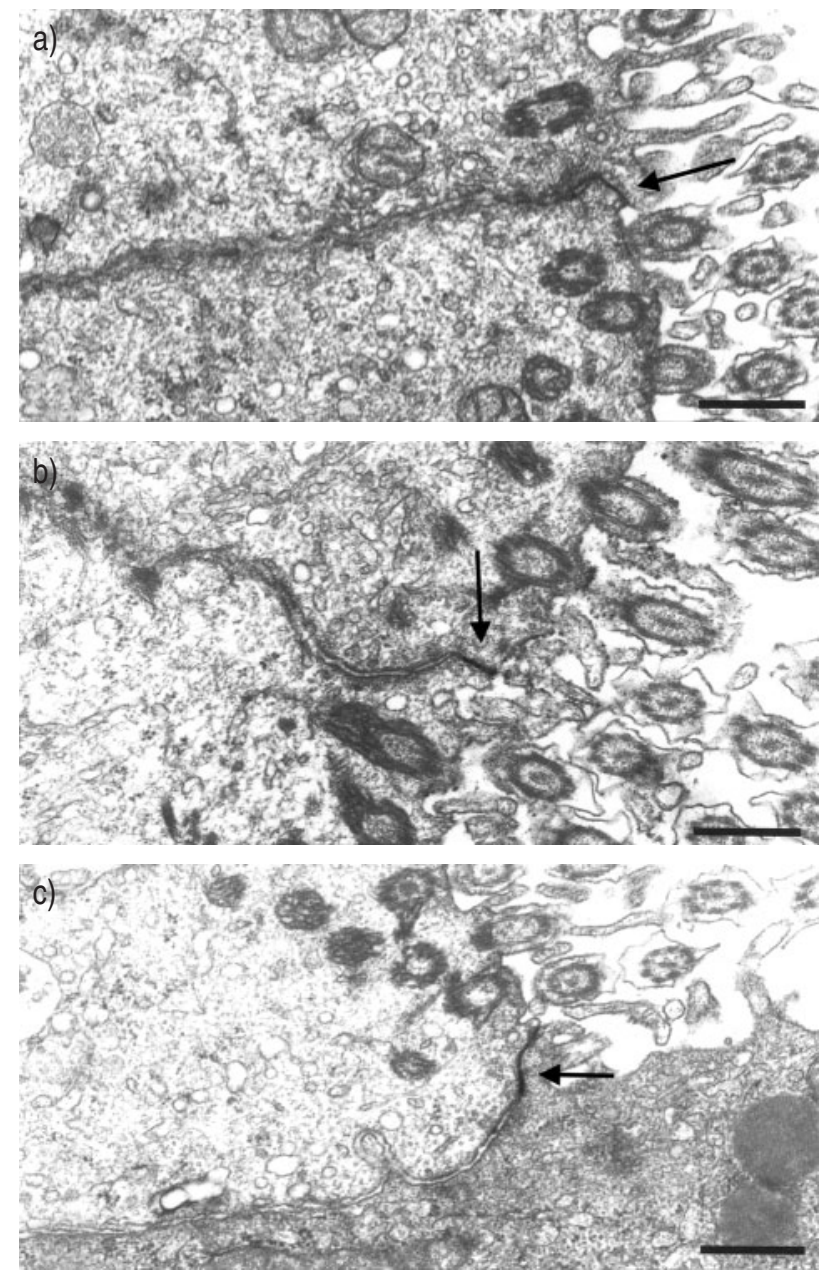

Fig. 1.- Transmission electron micrographs of airway epithelium perfused with Krebs-Ringer's buffer, and fixed in the presence of lanthanum. Some mild autolytic changes due to the incubation can be observed. a) Tight junction of the "intact" type: lanthanum has not penetrated the junction (arrow). b) Tight junction of the "weakened" type: lanthanum has penetrated a short distance into the tight junction (arrow). c) "Open" junction: lanthanum has completely penetrated the junction and is observed in the lateral intercellular space (arrow). Scale bars $=0.5 \mu \mathrm{m}$. 

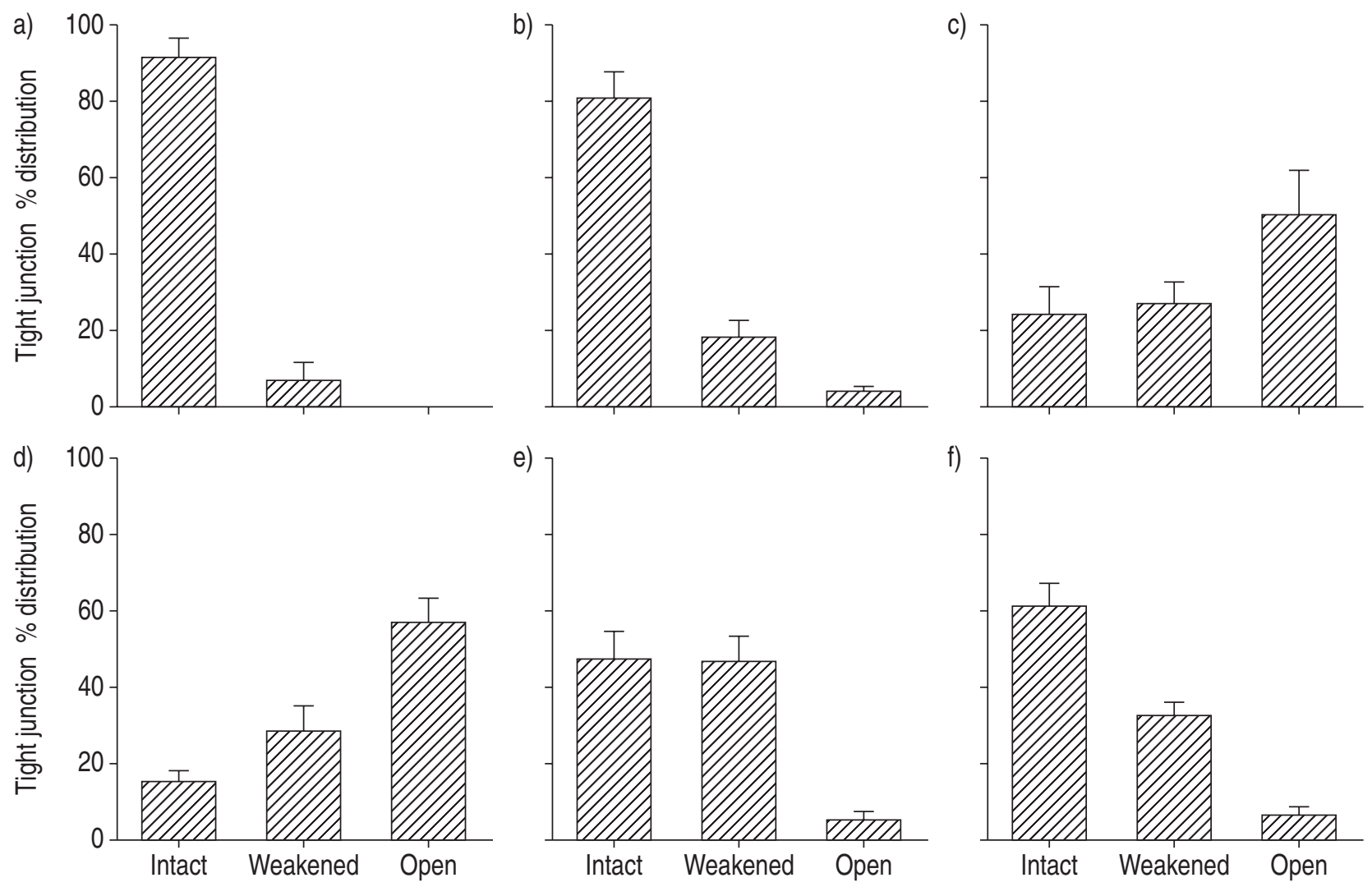

Fig. 2. - Quantitative results of the scoring of the tight junctions in a) in situ fixed trachea, b) trachea perfused with Krebs-Ringer's buffer (KRB; isotonic sodium chloride $(\mathrm{NaCl})$ ), c) trachea perfused with $\mathrm{KRB}-\mathrm{NaCl} 1.8 \%$, d) trachea perfused with $\mathrm{KRB}-\mathrm{NaCl} 2.7 \%$, e) trachea perfused with mannitol to a corresponding hyperosmolarity of $\mathrm{KRB}-\mathrm{NaCl} 1.8 \%$, and f) trachea perfused first with $\mathrm{KRB}-\mathrm{NaCl} 1.8 \%$ $\mathrm{NaCl}$, and then with isotonic KRB. Data are presented as mean \pm SEM (\%) of intact, weakened and open tight junctions.

were observed in this tissue (fig. 2a). In trachea perfused with isotonic $\mathrm{NaCl}$, a fraction of $0.80 \pm 0.14$ of the junctions were intact and $0.17 \pm 0.11$ were weakened; only the remaining $0.03 \pm 0.03$ of the junctions were open (fig. 2b). Perfusion with $1.8 \%$ or $2.7 \% \mathrm{NaCl}$ resulted in a decrease of the fraction of intact junctions, $0.24 \pm 0.15$ versus $0.15 \pm 0.06$, and an increase of the fraction of open junctions, $0.50 \pm 0.26$ versus $0.56 \pm 0.15$, with the remainder falling into the class of "weakened junctions" (figs $2 \mathrm{c}$ and $2 \mathrm{~d}$ ). ANOVA showed that this was significantly $(\mathrm{p}<0.001)$ different from tissue incubated in isotonic $\mathrm{NaCl}$. In addition, cells showed clear signs of shrinkage after incubation of hypertonic $\mathrm{NaCl}$ solutions (fig. 3a). After mannitol perfusion, the cells were obviously shrunken (fig. 3b), but only a few of the tight junctions were completely open, $0.05 \pm 0.04$, and of the remainder approximately one-half were intact and half weakened (fig. 2e). When tissue perfused with $1.8 \% \mathrm{NaCl}$ was subsequently perfused with isotonic saline for $2 \mathrm{~min}$, the number of open junctions was reduced, $0.06 \pm 0.03$, whereas the fraction of intact junctions was $0.61 \pm 0.11$, and the remaining fraction of tight junctions weakened (fig. 2f). This result was not significantly different from tissue perfused with isotonic saline alone. The fraction of opened tight junctions was significantly lower $(\mathrm{p}<0.001)$, and the intact junctions significantly higher $(\mathrm{p}<0.0001)$ than with $1.8 \% \mathrm{NaCl}$ alone. There was a negative correlation between the concentration of $\mathrm{NaCl}$ and the fraction of intact tight junctions $(r=-0.71, \mathrm{p}<0.0001)$.

\section{Discussion}

This study showed that hyperosmotic solutions of $\mathrm{NaCl}$ increase the permeability of the tight junctions of the airway epithelium in such a way that lanthanum ions can penetrate into the lateral intercellular spaces. The effect appears to be more than a nonspecific osmotic effect, since the phenomenon cannot be reproduced in the same way by a high concentration of mannitol, despite the fact that mannitol causes changes in cell shape that are certainly as severe as those caused by hypertonic $\mathrm{NaCl}$. It is therefore unlikely that the opening of the tight junctions is simply due to mechanical stress caused by shrinking of the cells. The effect also appears fairly rapidly reversible, since perfusion for $2 \mathrm{~min}$ with isotonic solution after $1.8 \% \mathrm{NaCl}$ lowers the number of open junctions from $50 \%$ to $7 \%$. Since polycations are potent openers of tight junctions $[15,16]$, it could be speculated that the fact that $\mathrm{Na}^{+}$ions carry a positive charge, whereas sugars such as mannitol do not, is of importance for the effect.

The observation of "open" junctions in the perfused control differs somewhat from the situation in situ 

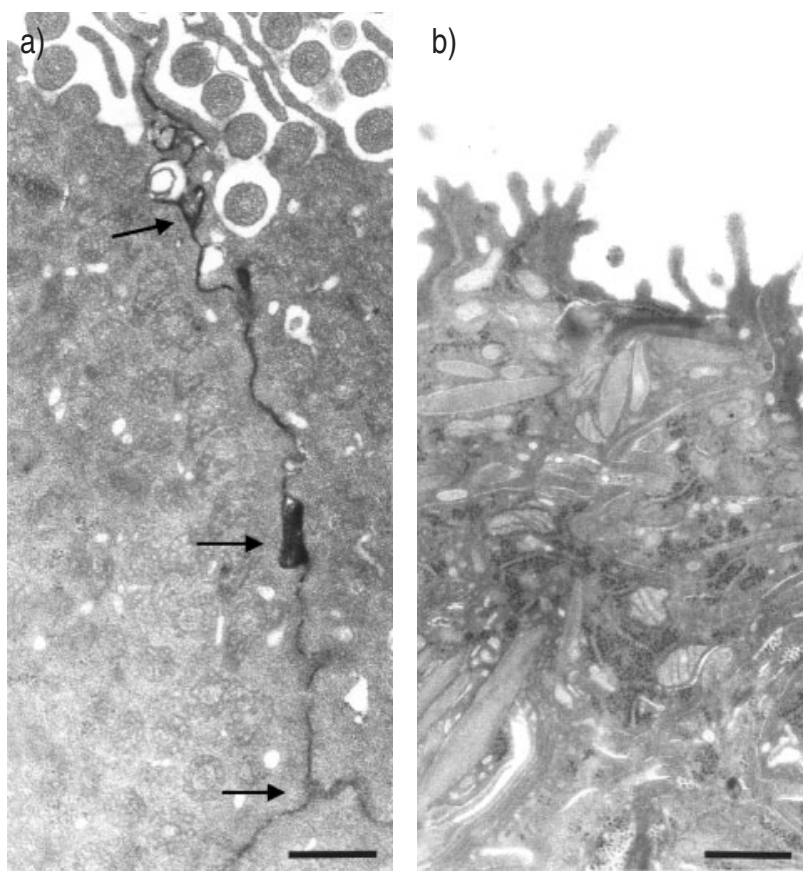

Fig. 3.-Transmission electron micrograph of airway epithelium a) perfused with Krebs-Ringer's buffer (KRB) with increased osmolarity by sodium chloride to $589 \mathrm{mOsm}$, and b) perfused with KRB with increased osmolarity by mannitol to $589 \mathrm{mOsm}$. In a) the electron dense lanthanum has penetrated into the lateral intercellular space (arrows), but in b) no lanthanum is visible in the intercellular space. In both cases, marked shrinkage of the cells is observed. Scale bar $=0.5 \mu \mathrm{m}$.

where no open junctions were observed. It is likely that, despite the fact that the trachea was perfused with oxygenated physiological buffer, the trauma of dissection and the suboptimal $\mathrm{O}_{2}$ supply have minor effects, for example, on intracellular ion concentrations, and calcium is known to be a factor influencing the permeability of tight junctions [17]. The mechanism by which $\mathrm{NaCl}$ causes opening of the tight junctions is unknown. Various substances have been shown to be able to affect tight junction permeability; the most universal of these are calcium and cAMP [18]. In addition, factors affecting the cytoskeleton are known to also affect tight junction structure [3]. It is conceivable that hypertonic $\mathrm{NaCl}$ acts by affecting the intracellular concentration of calcium ions and/or cAMP, or that it affects the structure of the cytoskeleton.

KRB was used as a "control" solution. Although the composition of the airway surface liquid has been intensively debated [10-12], there is increasing evidence that this liquid is (near to) isosmotic, and therefore KRB appears a reasonable choice for a control.

Since the structure of rat airway tight junctions is similar to that of tight junctions in the human airway [19], the finding that hypertonic $\mathrm{NaCl}$ may open up tight junctions may have several interesting clinical consequences. It is well known that exercise and dry air can cause bronchial hyperreactivity $[13,20]$. This effect is likely to be mediated by loss of water from the thin fluid film covering the tracheal mucosa.
This evaporation would give rise to formation of a hypertonic salt solution covering the mucosa, and, as shown in the present study, this could dramatically change the epithelial permeability by opening the tight junctions between the cells. This would make it easier for noxious agents or products from the immune system to pass the epithelium and penetrate into the subepithelial connective tissue, with which they would not come into contact otherwise.

It would also be possible to turn the weakening of the tight junctions into a positive event, if it would improve the transepithelial transport of the inhaled drugs that need to reach the interstitium and the circulation. For similar reasons, some authors have attempted to make the tight junctions of the endothelium of the brain capillaries ("blood-brain barrier") more permeable [21], and considerable effort has also been directed to research into making the tight junctions of the intestinal epithelium more permeable $[16,22,23]$. There has also been some interest in making the tight junctions of the respiratory epithelium more permeable in connection with gene therapy [24]. This has to be done, since for adenoviruses, for example, there is no receptor in the apical membrane but only in the basolateral membrane of the airway epithelial cells. Therefore, to infect these cells with a virus carrying a corrective gene, the virus has to pass the tight junction into the intercellular space. In a separate study (unpublished data), the authors have shown that treatment with hyperosmolar solutions permits passage of fluorescent dextran with a molecular weight of $\sim 4,500$ but not with $\sim 10,000 \mathrm{kD}$. This implies that, at this stage, the method would not facilitate the penetration of viruses in the intercellular spaces in connection with gene therapy.

The use of hypertonic sodium chloride as an aid to facilitate the movement of drugs through the respiratory epithelium would have several advantages. Since sodium chloride is a substance occurring naturally in the body, side-effects of the substance, as such, would not be expected to be a major problem. The body is well equipped to correct systemic effects of temporarily increased sodium chloride concentrations. Polycations, of which the use has been suggested in intestinal epithelia $[22,25]$, can be very damaging to airway epithelial cells $[15,26,27]$. Also, the calciumchelating agent egtazic acid, which was used by $\mathrm{CHU}$ et al. [24] to open up tight junctions to facilitate the passage of a virus in connection with gene therapy for cystic fibrosis, can have detrimental effects. Whether sodium chloride can be applied to other types of epithelia with the same results remains to be investigated. Preliminary results on intestinal epithelium showed that tight junctions were still intact, even after exposure to $3.6 \%$ sodium chloride. Hence, the effect of sodium chloride may be specific to a limited number of epithelia. This specificity is not surprising considering the fact that claudin, the most important protein of the tight junction, occurs in nearly 20 tissue-specific varieties [28]; e.g. claudin-5, is specific for the endothelial cell junction and thus relevant for the bloodbrain barrier, but does not appear to occur in the tight 
junctions of the respiratory epithelial cells. Apart from the tissue-specific nature of the junctions themselves, factors regulating tight junction permeability are also known to be tissue-specific [18]. Therefore, the effects of permeability-enhancing substances should be investigated for each particular epithelium and no claims can be made regarding general effects. However, in airway epithelium hyperosmolar sodium chloride could prove a suitable agent to facilitate the transport of inhaled drugs across the epithelium.

Acknowledgements. The authors are grateful to A. Ahlander and M. Ljungkvist for expert technical assistance.

\section{References}

1. Mitic LL, van Itallie CM, Anderson JM. Molecular physiology and pathophysiology of tight junctions I. Tight junction structure and function: lessons from mutant animals and proteins. Am J Physiol 2000; 279: G250-G254.

2. Tsukita S, Furuse M, Itoh M. Multifunctional strands in tight junctions. Nat Rev Mol Cell Biol 2001; 2: 258293.

3. Nusrat A, Turner JR, Madara JL. Molecular physiology and pathophysiology of tight junctions. IV. Regulation of tight junctions by extracellular stimuli: nutrients, cytokines, and immune cells. Am J Physiol 2000; 279: G851-G857.

4. Walsh SV, Hopkins AM, Nusrat A. Modulation of tight junction structure and function by cytokines. $A d v$ Drug Rev 2000; 41: 303-313.

5. Wilt SD, Rizzolo LJ. Unique aspects of the bloodbrain barrier. In: Cereijido M, Anderson J, eds. Tight Junctions. 2nd edn. Boca Raton, CRC Press, 2001; pp. 415-443.

6. Nguyen DD, Beeman N, Neville MC. Regulation of tight junction permeability in the mammary gland. In: Cereijido M, Anderson J, eds. Tight Junctions. 2nd edn. Boca Raton, CRC Press, 2001; pp. 395-414.

7. Turner JR, Madara JL. Physiological regulation of tight junction permeability by $\mathrm{Na}^{+}$-nutrient cotransport. In: Cereijido $\mathrm{M}$, Anderson $\mathrm{J}$, eds. Tight Junctions. 2nd edn. Boca Raton, CRC Press, 2001; pp. 333-347.

8. Anderson MP, Gregory RJ, Thompson S, et al. Demonstration that CFTR is a chloride channel by alteration of its anion selectively. Science 1991; 253: 202-205.

9. Welsh MJ, Anderson MP, Rich DP, et al. Cystic fibrosis transmembrane conductance regulator: a chloride channel with a novel regulation. Neuron 1992; 8: 821-829.

10. Boucher RC, Stutts MJ, Gatzy JT. Regional differences in bioelectric properties and ion flow in excised canine airways. J Appl Physiol 1981; 51: 706-714.

11. Baconnais $\mathrm{S}$, Tirouvanziam $\mathrm{R}, \mathrm{Zahm} \mathrm{JM}$, et al. Ion composition and rheology of airway liquid from cystic fibrosis fetal tracheal xenografts. Am J Respir Cell Mol Biol 1999; 20: 605-611.

12. Hull J, Skinner W, Robertson C, Phelan P. Elemental content of airway surface liquid from infants with cystic fibrosis. Am J Respir Crit Care Med 1998; 157: $10-14$.
13. Anderson SD. Is there a unifying hypothesis for exercise-induced asthma? $J$ Allergy Clin Immunol 1984; 73: 660-665.

14. Eschenbacher WL, Boushey HA, Sheppard D. Alterations in osmolarity of inhaled aerosols cause bronchoconstriction and cough but absence of a permeant anion cause cough alone. Am Rev Respir Dis 1984; 129: 211-215.

15. Shahana S, Kampf C, Roomans GM. Effects of polyL-arginine on airway epithelial cells in vitro. Mediators Inflamm 2002; 11: 141-148.

16. Karlsson J, Ungell A, Gräsjö J, Artursson P. Paracellular drug transport across intestinal epithelia: influence of charge and induced water flux. Eur J Pharm Sci 1999; 9: 47-56.

17. Bentzel CJ, Palant CE, Fromm M. Physiology and pathological factors affecting the tight junction. In: Cerejido $\mathrm{M}$, ed. Tight Junctions. Boca Raton, FL, CRC Press, 1991; pp. 151-173.

18. Karczewski J, Groot J. Molecular physiology and pathophysiology of tight junctions III. Tight junction regulation by intracellular messengers: differences in response within and between epithelia. Am J Physiol 2000; 279: G660-G665.

19. Godfrey RWA, Severs NJ, Jeffery PK. A comparison between the epithelial tight junction morphology of human extrapulmonary bronchi and rat trachea. Eur Respir J 1994; 7: 1409-1415.

20. Freed AN. Models and mechanisms of exerciseinduced asthma. Eur Respir J 1995; 8: 1770-1785.

21. Adler S, Verbalis JG, Williams D. Effect of rapid correction of hyponatremia on the blood-brain barrier of rats. Brain Res 1995; 679: 135-143.

22. Thanou MM, Verhoef JC, Romeijn SG, Nagelkerke JF, Merkus FW, Junginger HE. Effects of N-trimethyl chitosan chloride, a novel absorption enhancer, on Caco-2 intestinal epithelia and the ciliary beat frequency of chicken embryo trachea. Int $J$ Pharm 1999; 185: 73-82.

23. Thanou MM, Kotze AF, Scharringhausen $\mathrm{T}$, et al. Effect of degree of quaternization of $N$-trimethyl chitosan for enhanced transport of hydrophilic compounds across intestinal caco-2 cell monolayers. J Controlled Release 2000; 64: 15-25.

24. Chu Q, St George JA, Lukason M, Cheng SH, Scheule RK, Eastman SJ. EGTA enhancement of adenovirus-mediated gene transfer to mouse tracheal epithelium in vivo. Hum Gene Ther 2001; 12: 455467.

25. Kotze AF, Thanou MM, Luessen HL, de Boer BG, Verhoef JC, Junginger HE. Effect of the degree of quarternization of $\mathrm{N}$-trimethyl chitosan chloride on the permeability of intestinal epithelial cells (Caco-2). Eur J Pharm Biopharm 1999; 47: 269-274.

26. Hülsmann AR, Raatgeep HR, den Hollander JC, Bakker WH, Saxena PR, de Jongste JC. Permeability of human isolated airways increases after hydrogen peroxide and poly-L-arginine. Am J Respir Crit Care Med 1996; 153: 841-846.

27. Ko KH, Lee CJ, Shin CY, Jo MJ, Kim KC. Inhibition of mucin release from airway goblet cells by polycationic peptides. Am J Physiol 1999; 277: L811L815.

28. Heiskala M, Peterson PA, Yang Y. The roles of Claudin superfamily proteins in paracellular transport. Traffic 2001; 2: 93-98. 